\title{
Unveiling everyday reflexivity tactics in a sustainable community
}

Article

Accepted Version

Casey, K., Lichrou, M. and O'Malley, L. (2017) Unveiling everyday reflexivity tactics in a sustainable community. Journal of Macromarketing, 37 (3). pp. 227-239. ISSN 0276-1467 doi: https://doi.org/10.1177/0276146716674051 Available at https://centaur.reading.ac.uk/89555/

It is advisable to refer to the publisher's version if you intend to cite from the work. See Guidance on citing.

To link to this article DOI: http://dx.doi.org/10.1177/0276146716674051

Publisher: SAGE

All outputs in CentAUR are protected by Intellectual Property Rights law, including copyright law. Copyright and IPR is retained by the creators or other copyright holders. Terms and conditions for use of this material are defined in the End User Agreement.

\section{www.reading.ac.uk/centaur}

\section{CentAUR}

Central Archive at the University of Reading

Reading's research outputs online 


\title{
Unveiling Everyday Reflexivity Tactics in a Sustainable Community
}

Katherine Casey, University of Limerick, Limerick, Ireland

Maria Lichrou, University of Limerick, Limerick, Ireland

Lisa O’Malley, University of Limerick, Limerick, Ireland

\begin{abstract}
Approaches to enhancing sustainability have largely focused on altering individual consumption behaviours. However, this focus on the individual consumer has been recently critiqued because the behaviour of individuals is situated within wider socio-cultural contexts. Thus, the sustainability research agenda is shifting away from individual consumers towards understanding consumption practices, social networks, material infrastructures and organisations of various forms in which consumption is problematized and consumption choices are reflected upon and negotiated. These social spaces need to be understood if change is to be truly achieved. Drawing on ethnographic research conducted in an Irish Eco Village, we examine how ecovillage members negotiate sustainable consumption at the everyday level. Analysis reveals how members of the ecovillage employ tactics that encourage reflexivity in the everyday. Specifically, these reflexive tactics work together to confront routine consumption, create alternative infrastructures that support sustainability, and foster critical engagement.
\end{abstract}




\section{Introduction}

This paper addresses how the complex and nebulous eco-discourse of sustainability is enacted in the everyday. Population, production and consumption are at the heart of academic, policy and popular discourses on sustainability because they are all inextricably implicated in advancing environmental degradation (Hobson 2002). Of these, consumption attracts significant attention because "consumerist values are assumed to lead to unsustainable consumption" (Holt 2012, p. 239). Indeed, rising consumption levels in the developed world are acknowledged to be a major impediment in the transition to a sustainable society (Assadourian 2010; Hobson 2002). Within marketing, a considerable body of work has addressed how the discipline is implicated in the problem and how it can contribute to enhancing sustainability (McDonagh and Prothero 2014). In terms of the latter, efforts to reduce aggregate consumption levels by influencing individual consumer behaviour (Schaefer and Crane 2005) have been most popular, together with efforts to understand and support the environmentally conscious consumer (see Kilbourne and Beckmann 1998; McDonagh and Prothero 2014). Sustainable solutions have been discussed under numerous designations including, but not limited to, "ethical consumption" (Harrison, Newholm, and Shaw 2005), "political consumption" (Boström et al. 2004; Micheletti 2003), "alternative consumption" (Bryant and Goodman 2004) and "green consumption" (Peattie 2010). We use the term "sustainable consumption", introduced at the 1992 Rio Summit and defined as "the use of goods and related products which respond to basic needs and bring a better quality of life, while minimising the use of natural resources and toxic materials as well as the emissions of waste and pollutants over the life cycle, so as not to jeopardise the needs of future generations" (Seyfang 2006, p. 384).

Given increased recognition that the behaviour of individuals is situated within wider socio-cultural (Dolan 2002) and spatio-temporal contexts (Chatzidakis, Maclaran, and 
Bradshaw 2012) the focus on the individual consumer has been critiqued (Dolan 2002;

Schaefer and Crane 2005). Consequently, the sustainability research agenda is shifting towards consumption practices, social networks, material infrastructures and organisations of various forms (Clarke 2008; McDonagh and Prothero 2014b; Prothero and McDonagh 2015). Recent studies reveal social spaces in which consumption is problematized and consumption choices are reflected upon and negotiated. For example, critique and experimentation in Exarcheia, an urban neighbourhood in Greece, led to new ways of thinking and doing ecological behaviours (Chatzidakis, Maclaran, and Bradshaw 2012). This highlights how space and place are essential to questions of ethics, politics, and ecology. Our interest in understanding how the eco-discourse of sustainability in the everyday lives of Cloughjordan Ecovillage (CJEV) in Ireland.

Ecovillages are relatively recent phenomena that have experienced rapid growth since the early 1990s. As the name suggests, an eco-design is combined with a focus on community (Chitwere 2010). Ecovillages are organised around the concept of sustainable living. Initially associated with downsizing and voluntary simplicity (Schor 1998), there are now many very different types of ecovillage in terms of location, composition and degree of "greenness" (Ergas 2010). While originally associated with living very differently, often in isolated, protected settings (Schehr 1997) contemporary ecovillages engage more with the dominant culture than was previously the case (Ergas 2010). Members of these communities are driven by a multitude of motivations; connecting with other like-minded individuals, deviating from the accepted social modes, creating spaces of resistance and the possibility to live as environmental citizens (Kirby 2003; Moisander and Pesonen 2002). CJEV is an example of a contemporary ecovillage.

The paper is organised as follows: First we explore the conceptual shift from a focus on individual consumption behaviour towards an appreciation of how sustainable 
consumption is supported by social networks, material infrastructures and organisations.

Second, we elaborate on the context of this research, an Irish ecovillage in which the macro consumer discourse of sustainable consumption and related practices are shared, negotiated and made meaningful among members in their everyday lives. Third, we delineate the methodological approach adopted in this study. Fourth, we interrogate how members of this ecovillage employ tactics that encourage reflexivity in the everyday. Specifically, these reflexive tactics work together to confront routine consumption, create alternative infrastructures that support sustainability, and foster critical engagement. Finally, we offer conclusions and implications for policy makers and outline directions for future research.

\section{Towards Understanding Sustainable Consumption in Context}

Considerations of sustainable consumption have often relied on a rationalist, informationprocessing view of consumption (Dolan 2002; Schaefer and Crane 2005). Here individual consumer preferences are regarded as both the cause of and, solution to, the ecological problem. Individual consumers thus carry the burden and responsibility of sustainability through the choices they make. This is in line with the prevailing neo-liberal principle of consumer sovereignty in a free market economy. Which assumes that when "individuals care about the environment, it will be translated into preferences that are expressed through acts of consumption" (Hobson 2002, p. 100). Consumers' sustainable choices will therefore, generate demand for sustainable products and services to which producers and marketers will respond. As a result, much research and policy have focused on changing values and attitudes towards sustainable consumption choices (Holt 2012; Schaefer and Crane 2005). This explains why environmental initiatives are typically preoccupied with overcoming the "attitude-behaviour gap" and the inclusion of environmental criteria in individual consumer decision-making. The focus of this approach is to change individual behaviour through 
changing preferences rather than to engender social and cultural transformation. In so doing, it leaves the dominant social paradigm (DSP) (Kilbourne, McDonagh, and Prothero 1997) largely unchallenged.

Given the limitations of focusing on individual consumer behaviour, attention is being directed towards consumption practices, social networks, material infrastructures, and organisations (Clarke 2008; McDonagh and Prothero 2014b; Prothero and McDonagh 2015). For example, within macromarketing, Scott, Martin, and Schouten (2014) argue that failure to be sustainable is less about individuals' values and more about the practices and infrastructures that facilitate unsustainable production and consumption. The bottled water market is a good illustration of this. Fuelled by cultural transformations in the late 1980s, consumption of bottled water emerged as a powerful market ideology and embedded everyday practice (Holt 2012, p. 248), with the single serve bottle water market constructed and reproduced over time in America. Despite recognition that bottled water is not good for the environment, and not always good for one's health, efforts to change individual behaviour have had little impact because they fail to address the market ideology and structures that fuel its consumption (Holt 2012).

In addition to ideological and institutional systems that support unsustainable consumption practices, there are many non-institutional sustainable practices that are not supported, and, indeed, are often discouraged. For example, gleaning (retrieving disposed objects from the sidewalk) involves various tensions and negotiations with the prevailing hygienist norm (Guillard and Roux 2014) and is thus not widely encouraged. Concomitantly, freeganism, a combination of free/shared resources (often liberated from dumpsters) is marginalised and/or criminalised (Pentina and Amos 2011). Engagement in consumption practices that are not sustained by institutional ideologies and structures can therefore be challenging. 
A critical school of macromarketing thought has emerged which challenges the tenets of the DSP (see Mittelstaedt et al. 2014). In particular scholars question "the degree to which sustainability can be achieved within the context of Western, neoliberal patterns of thought and behaviour" (Kilbourne 2010, p. 109). This opens up the agenda for "culturally sensitized accounts of structural transformation that assert the intersection of micro-level logics and practices with macro-level socio-political change" (Chatzidakis, Larsen, and Bishop 2014). Such accounts are cognisant of the culturally situated, spatialized and political (see Chatzidakis, Maclaran, and Bradshaw 2012) nature of sustainable consumption practices. In treating consumer practices as social practices (Dolan, 2002), we borrow from the sociology of consumption, which examines consumption as a field of everyday life.

Everyday practices are capable of creating and recreating social order (Hobson 2003) allowing more sustainable approaches to everyday life to emerge. Consumption practices involve routinized and reflexive activities. Routines are carried out without much awareness or reflection on the part of the individual but serve to provide us with a sense of normality (Ilmonen 2001). On the other hand, reflexivity is intentional and reflexive activities are intended to address problematic practices (Halkier 2001). However, this distinction is not always clear. Recent work recognises the import of examining socio-spatial contexts in which consumption routines are problematized and reflexive consumption practices emerge as a form of resistance to conventional consumption. Such contexts foster critique of the DSP and encourage experimentation with alternative consumption discourses and practices (Chatzidakis, Maclaran, and Bradshaw 2012; Halkier 2001; Kozinets 2002). For example, Exarcheia, an Athenian neighbourhood characterized for its radical ethos, has become a site for utopian praxis, fostering critique, experimentation, and new ways of thinking and doing consumption (Chatzidakis, Maclaran, and Bradshaw 2012). Space and place play an important role in the formation of "heterotopias of resistance", places that are capable of 
challenging the ruling norms and are thus "important sites of difference and rebellion" (Chatzidakis, Maclaran, and Bradshaw 2012, p. 497). Radical forms of consumer-oriented activism are informed by a shared countervailing ideology, which is reflected in everyday consumer logics and practices (Chatzidakis, Larsen, and Bishop 2014; Portwood-Stacer 2012). Consumption practices therefore involve tactics used by particular consumers to enact ideological discourses. In this sense, consumption practices are spatialized and political (Chatzidakis, Maclaran, and Bradshaw 2012). It is useful, therefore, to explore the connections between micro level everyday consumption practices and macro level political discourses on sustainability.

This paper contributes to this dialogue by exploring reflexive tactics in Cloughjordan Ecovillage (CJEV) in Ireland. Physically located within an existing village, it was designed to be both ecological and community oriented. It claims to be a "model of sustainable living" a position validated by its receipt of the "International Award for Liveable Communities" (The LivCom Awards 2014) which recognizes "innovative projects which demonstrate sustainability and environmental awareness, and have a positive impact on the local community and environment" (The Village 2013). CJEV engages with the dominant culture both spatially and politically. As such, it is a particularly interesting research site to unveil the challenges of negotiating sustainability in a $21^{\text {st }}$ Century developed economy.

Focussing on reflexive tactics, this paper reveals how members translate this macro level discourse of sustainability into micro level everyday practices. Our use of reflexive tactics relies on notions of reflexivity developed within theories of reflexive modernity. Following Connolly and Prothero (2008), reflexivity involves the building and rebuilding of a coherent sense of identity. Reflexivity is thus a process that has the potential to transform one's life and as such can be liberating and empowering. Members use tactics, individually and collectively, to encourage engagement with sustainability, and ultimately, transform their 
consumption practices. As such, the abstract eco-discourse of "sustainability" is integrated into the everyday.

Discourse can be viewed as “a network of social practices” (O’Sullivan 2007, p. 296). People use language, listening and speaking, to construct meanings and understandings which then inform their behaviours (Kornberger and Brown 2007). Thus there is an iterative relation between discourse, meaning and practice. This approach recognises discourse as constitutive of the social world, that is, the world cannot be understood as separate from discourse (Phillips and Hardy 2002). Thus, organisations (such as this ecovillage) are socially constructed by their members (Berger and Luckmann 1966). Discourse expresses, reproduces and enacts ideology (van Dijk 2006); it is a system of formation and articulation of ideas (Alvesson and Karreman 2000). Discourse can therefore, be regarded as "language-inaction" (Blommaert 2005, p. 2) and "are communicated through different kinds of semiotic resources, different modes, and realized through different genres" (Machin 2013, p. 347). In order to access how the abstract eco-discourse of sustainability is integrated in the everyday in the context of CJEV, we interrogate the "interrelated set of texts, and the practices of their production, dissemination and reception" (Phillips and Hardy 2002, p. 3) that inform life in CJEV.

\section{Methodology}

An ethnographic approach was adopted in order to gain access to the ecovillage members' everyday life. It is at this level that norms become concrete and manifest themselves as a form of "lived ideology" (Askegaard and Linnet 2011, p.396). Admission was obtained via the community appointed gatekeeper and an email, outlining the purpose of the study, was used to recruit the first five interviewees. The fieldwork consisted of five week-long periods of immersion (table 1). 
[Insert table 1 about here]

Because outsiders regularly volunteer to work on the farm the lead researcher spent several days as a volunteer. This provided informal access to the community which resulted in invitations to several events including community meals, social evenings and farm meetings. During these periods the researcher had numerous informal conversations with members and volunteers which would later lead to interviews. Autoethnographic fieldnotes were taken in order to encourage critical and sociological thought and foster critical reflexivity (Denzin 2003). Fieldnotes were taken using OneNote, a Microsoft note taking multi-platform application, OneNote is available on mobile phones and thus allowed ease of access.

Sixteen in-depth interviews were conducted which lasted, on average, between one and two hours. Interviews were recorded in OneNote and fully transcribed (see table 2). Interrogation was supported by "Dedoose", a software package which facilitates the application of codes and categories to the data and reimagines the traditional "copy and paste" function in Word. Dedoose allows us to deconstruct the data and then reconstruct it.

Additional data sources were also interrogated, they included the ecovillage website, internal documentation and photographs. This rich ethnographic data was analysed through Discourse Analysis (DA).

\section{Table 2}

In each reading we were very sensitive to the discourses drawn on and the language employed. For the purposes of this paper we are interested in how these discourses are enacted in the everyday and, thus we are concerned, not only with language, but also with practice (Blommaert 2005). Importantly within the context of CJEV we noticed how images and artefacts were used to convey discourse (see also Stibbe 2015). 
Thus Multimodal Discourse Analysis (MDA) was used to access meaning in images and artefacts and locate this meaning within wider discourses. The first stage of analysis is the identification the location of the image or artefact, it's form and composition. The second stage explores how ideas and values are connoted through the image or artefact and how they relate to broader discourses (Kress and Leeuwen 2006; Machin and Mayr 2012; Stibbe 2015). The use of software packages to support MDA are not widely available and in any case are used only to supplement traditional methods of analysis and not to replace them (O'Halloran et al. 2011; Machin and Mayr 2012).

MDA thus facilitated a deeper understanding as to how members express the dominant ideologies, both within the community and to the general public. Analysis unearthed how the eco discourse of "sustainability" manifests in this context and exposed "reflexive tactics" used at an individual and a collective level. Revealing how the ecodiscourse of "sustainability" manifests in this context and exposed "reflexive tactics" used at an individual and a collective level.

\section{Cloughjordan Ecovillage}

As a model of sustainable living CJEV is explicitly open to researchers and visitors for educational and familiarisation field trips. Members invite the public into their ecologically designed homes thereby blurring the line between being a private consumer and a public citizen.

[insert figure 1 about here]

"I could take myself out to the woods and buy a cabin in the outback of Canada and live a completely separate life or I could sit up in the side of a mountain or a hill and only eat what I can eat and sort of exist outside of life. But I do exist, I accept that I do exist in a 
world I don't want to completely abandon that world, I don't want that sort of...we could have created a village where, an ecovillage where we are sort of a hippie commune out in a field somewhere, where we are completely removing ourselves from the rest of society. But instead, no, we chose not to. We exist in a society and I recognise that." (Marcus)

Marcus alludes to the mainstream discourse around existing ecovillages, and, in particular, the popular idea that they are isolated "hippie communes". He creates a dualism between that type of community and the one which they have created, a community which recognises its place in the contemporary world. The community's embeddedness is illustrated not only by their physical location but also by commitment to changemaking in the local community.

"But we are right here in the heart of the [town]. Most importantly the kids are going to school, there was talk at one stage about building a Steiner school here in the ecovillage. I think that would be an absolute disaster, it would be the worst thing that could possibly happen $[\ldots]$ To not have that integration of the people, the parents meet at the school gates, the kids playing with each other, and all of that. That's so, so important." (David)

David supports Marcus' contentions. He highlights the importance of the community decision not to create a Steiner School, a type of school often associated with ecologically informed lifestyles (Craig-Lees and Hill 2002; Moraes, Szmigin, and Carrigan 2010). Community integration is a priority for members of this eco-neighbourhood. This pragmatic approach to sustainability and $21^{\text {st }}$ Century life is shared by many of the members, acknowledgement that to exist one has to engage with society, with the market and thus, with the DSP.

The particularity of this ecovillage is that compared to intentional communities with deep ecological orientations (see for example Pickerill 2015), this community takes a less radical approach to sustainable living. Participants distinguish the 
ecovillage by virtue of its location which is physically part of the village. Indeed, some use the term eco-neighbourhood to highlight their co-existence and integration with the wider community. This is borne out in the members' commitment to bringing positive change to the local community. Some members work with local agencies to further sustainability in the larger area. Examples of such work include securing social and environmental grants, and the building of an eco-enterprise centre, a local crèche and Heritage Centre. This connectedness with CJEV's broader social context is important to the members. In doing so, members actively foster a relationship with the public and view their interactions with the wider community as a key distinguishing feature. Furthermore, there is a strong focus on reflexivity around sustainable practices, modes of consumption and related behaviours. CJEV has recently planted 20,000 trees and boasts Ireland's largest renewable energy district heating system (DHS) (Kirby 2014). Features of the ecovillage include a permaculture landscape design, low energy homes, a renewable energy centre, several civic spaces, woodland gardens, a community farm, a green enterprise centre, and an educational centre. Several members engage with academic research on sustainability.

The ecovillage is a cooperative. All members are shareholders in a registered educational charity, named Sustainable Projects Ireland Limited (SPIL), trading under the name The Village. At present, CJEV has over one hundred residents, living in 55 sustainable homes. Construction is on-going to complete a planned total of 130 homes. Members tend to be long-term as they own their homes, and many have substantial mortgages as a result.

The Village engages in consensus decision-making. The members have subscribed to a paradigm of self-organisation and therefore share all the responsibilities associated with the ecovillage (The Village 2016) ${ }^{\mathrm{i}}$. The Village Charter outlines the values and objectives of the CJEV (Cunningham 2014). The charter establishes a number of targets for the ecovillage in relation to land use, energy use and community issues (social and communal facilities). 
Furthermore, SPIL discourages the use of cars; to this end the roads within the ecovillage are narrow (4.5 metres) and each house is allocated only one car space (Kirby 2014).

CJEV established consumption targets which they actively monitor. Using various tools the members collectively reflect on their consumption and disposal behaviours. For example, in comparison to the average Irish household, which uses 6.2 global hectares (gHa), CJEV require just $2 \mathrm{gHa}$ per household (The Village), which is just above the global target of 1.8gHa (Borucke et al. 2012). Although a positive achievement, members acknowledge that the real value of engaging with this audit was to identify 'problematic areas', such as car usage, energy consumption, meat consumption and disposal methods, which need redress.

Politically orientated eco-discourses feature heavily in the ecovillage. Discourse works to ensure that "certain phenomena are created, reified, and taken for granted" (Phillips and Hardy 2002, p. 21). Aware of this, members foster reflexivity, criticality and debate.

\section{Reflexive Tactics Unveiled}

Members of the ecovillage employ a set of inter-related tactics that encourage reflexivity in the everyday. They are designed to un-silence and thus problematize the conventional cycle of production, consumption and disposition, and, to facilitate critical engagement with sustainability rubric and rhetoric. These tactics: foster reflection among themselves and others around consumption; encourage more sustainable practices, and; facilitate alternative modes of consumption. Reflexive tactics thus allow members to frame and reframe what they understand by sustainability and to enact the macro eco-discourse to which they subscribe in their everyday lives. 


\section{Confronting Routine Behaviours}

This section examines two tactics that confront routine (often invisible) behaviours that are environmentally damaging (de Coverly et al. 2008; Hobson 2003). These are primarily for visitors and are intended as educational in nature. Conversations with members and personal observations revealed that, while members have generally positive views about such tactics, they are not deployed in most private homes. Visual and physical artefacts are primarily used for display in public spaces in order to engage others in reflexive thinking about the cycle of consumption and the role which they play.

The first tactic invokes reflexivity in relation to energy consumption by guests. While the ecovillage has addressed energy consumption sustainable construction, for many visitors, everyday electricity consumption is inscribed in less reflexive practices (Halkier 2001). For example, electricity is often perceived as a "necessity" not a "choice". It is therefore largely invisible because it is not consumed as a product in itself, rather it facilitates other activities, such for example laundry, cooking, and reading (Vliet, Chappells, and Shove 2005, p. 14). As can be seen in figure 2, the tactic involves the demarcation of the light switches in the communal area of the ecovillage hostel. An oil rig and a fossil fuel power station are both stencilled around light switches in the communal area. This tactic serves to directly confront and problematize how electricity is generated.

[Insert figure 2 about here]

The words "oil" and the carbon dioxide symbol "CO2" feature prominently and depict the destructive multistage process through which electricity becomes available for consumption. The colour choice is important. A black gloss emanates a certain "oiliness" and visually resembles carbon. Contrasted with a white background the stencils create eyecatching images. The image of the oil rig signifies a journey from the ocean floor, via a rig, to the switch and from the switch, via a power station into the atmosphere. The image and its 
representation are intentional, and can be perceived as another mode of discursive and ideological enactment. The oil rig points to the petroleum extracted for the purposes of electricity. Mid-way across the bottom of the light switch a large drop entitled "oil" escapes the pipeline. Emissions rise from two points of the rig explaining the polluting qualities of oil to viewers, and reminding them that this is an ecovillage.

Importantly, the paint demarcates the switch. Light switches are typically mundane and not intended as features in a room. In making the switch stand out, the image invokes reflection on the role it plays in everyday life. The stencils do not impede usage of the lights, they do not reprimand the user but they highlight the significance and implications of using the light. This tactic therefore renders visible the significance of electricity consumption. It is worth noting that the photo is typical of all of the light switches in the communal areas in the eco-hostel. This is a public space and therefore this tactic serves to engage guests with the discourse of sustainability, and, importantly to foster critical thought around energy production. If energy conservation alone had been the intention motion sensors could have been installed to turn off the lights when appropriate; however, motions sensors would have not communicated meaning.

"Oh yeah that's all part and parcel of, I mean I would see that again because we would be very much in the public eye profile in that a lot of strangers would be coming down here that I would be doing as much as I can to promote the core philosophies that the village would be in favour of like, you know, awareness protection of the ecology and the rest of it." (David)

This is often the first place which visitors see and thus David sees it as crucial that the building reflects the village's "core philosophies". It is intended as a confrontation, as indicated by David's choice, he does not hang posters which encourage sustainable living nor 
does he hand out flyers. His choice is more personal and his message applicable beyond the ecovillage.

The problematisation of energy production is a common theme within the sustainability discourse (Kilbourne and Carlson 2008; Seyfang 2004) and serves to inform sustainable consumption. Members take an active role in the proliferation of this discourse. These depictions are good examples of how this discourse manifests in a material and very meaningful way. While the stencils on the light switch are intended to encourage reflexivity prior to consumption, other tactics encourage visitors to reflect on what happens after consumption. Indeed, for many members, disposition is a fundamental issue which needs to be addressed:

"The ideal green consumer also thinks about 'where is this going to end up when I've finished using it' and I think that's one thing that's one thing that very few people think about" (Thomas)

Thomas does not define the "ideal green consumer" merely in terms of how they consume. He draws attention to the importance of disposition, a view which is held closely by many members of this community. They are fervent recyclers, they dispose of food waste in an "anything goes" compost heap (which is later used on their farm) and they leave unwanted goods in a shed for collection by anyone who needs a stroller or an easel. However, despite these measures some waste is still disposed of via the local landfill. This is highly problematic for the ecovillage community, because the ever expanding landfill waste is at the heart of the ecological problem (de Coverly et al. 2008). The second tactic presented here employs a physical artefact (a rock) confronting routinized behaviours that lead to landfill waste. Figure 3 shows the deliberate placement of a black rock on the top of an indoor bin in the kitchen area of a member's house. It is important to note that albeit a residence, the house is open to guests and as such not strictly a private space. 
[Insert figure 3 about here]

"I had just asked him where the bin was, he answered my question with another: "Do you want to put that in the landfill?" I was at once disarmed, I felt hugely uncomfortable and made keenly aware of my irresponsible behaviour. "No, best not, it is just food and can be thrown out the window for some critter". The following day the bin bore a large rock, stubbornly holding the lid in place. I would be more mindful of my waste disposal in future."

(Fieldnotes from November 2013)

The rock brings about a degree of mindfulness as one must lift it to use the bin. This means that physical effort is now required to complete an action that usually requires no effort and is done without any conscious thought. The rock is implicated in the resignification of an ordinary domestic object; the bin. The bin takes on new meaning, as it is transformed from an object that serves the convenient and quick disposal of waste (de Coverly et al., 2008) into an object that demands confrontation with one's waste. This contrasts with systemic disposition and waste management practices that allow society to avoid dealing with the inevitable consequences of consumption (de Coverly et al., 2008) and facilitate hyperconsumption within the DSP (Kilbourne, McDonagh, and Prothero 1997). Here, the reflexive tactic of placing a rock on the bin is used to trigger the exact opposite effect. It is intended to make us confront what happens to our waste at the everyday level, and, ultimately, to unsilence our experiences of waste.

In unveiling the links between electricity production, consumption and waste disposition, visitors are confronted with the reality that consumption does not exist in a vacuum. Rather, it is flanked by production and disposition, processes which are masked by the current DSP (de Coverly et al. 2008). Both tactics in this section are communicative in nature; they convey information and engender reflexivity around consumption or disposition. 


\section{Creating Alternative Infrastructures}

Members seek to address identified 'consumption problems' as a community, creating alternative infrastructures that facilitate sustainable consumption. Car usage is considered to be heavily implicated in climate change (Sperling and Gordon 2009) and this was addressed in the village's design. However, access to transport is important in rural Ireland, and addresses important issues like convenience, freedom and safety (Hobson 2003). Therefore, transport is an issue which is heavily debated, and the presence of cars has become a contentious issue around revealing deep tensions.

"Some of the things which were being talked about at the early stages were quite deep green. For example should there be cars in the eco-village at all? You could, I think I would argue, actually that if I was starting the whole thing again I would have an absolutely no cars rule. That's not to say that you can't own a car but it stays outside the eco-village, in a garage on the edge of the village. In the community itself there would be no cars. There would be people who just would say that's not for me and that's fine but I think you're much clearer about what you're doing. But I think a decision was taken at a fairly early stage that if we were going to look at a site in rural Ireland the lack of public transport would mean that for a lot of people it would be just not thinkable not to have a car at their door." (Thomas)

Thomas describes the ideological discord which persists around transport, the lack of satisfactory public transport and the consequential perceived necessity for private car ownership. Despite the fact that many members viewed car ownership negatively, it became evident that, for some, the rural location of the ecovillage demanded access to a car. As a result, over time a lift sharing system emerged organically. Eventually members decided to rationalise this process and a formal not-for-profit car share club was created and run by a small number of volunteers. This is an important infrastructure within the ecovillage which facilitates sustainable consumption behaviours at a very real and personal level. 
"I won't get a car. I'll just wait till a space goes up in the community car scheme. There's three community cars but you have to wait till there's space... I don't know who technically owns it, I don't know if it's like one person has to own it for tax or insurance... so for example if I did something in Birr every Tuesday... I could just schedule that in but then I could also schedule in 'oh my friends are going to be in Thurles on Saturday, so I am going to take the car' so is the car is free on Saturday? And you look at the schedule and it's on google docs so it's available to everybody. So, I think certain things are set in stone and that works and then other things are like 'oh this is going on' is the car free? "(Jessica)

The existence of the car sharing club has a positive impact on Jessica's life. It is an important infrastructure that makes her lifestyle choices viable without car ownership. Whereas Jessica describes access in terms of the freedom which it bestows, Marcus is attracted by the reflexivity which this tactic compels.

"When you don't have a car and you need to...when you have a car that's all ready, you've got the keys there and the car is right there then it's easy to just make that trip but if you have to book the shared car and go and if it's a little bit farther then it makes you question whether you need to take that trip and if you are going to take that trip you might as well do a whole bunch of other things while you do that trip instead of saying 'yeah I'll do that tomorrow'." (Marcus)

For Marcus sharing access to a car obliges him to reflect on how he uses the car, requiring consideration as to what chores must be done and how best to do them in ways that benefit the community. This has the cumulative effect of reducing the number of trips made and nurtures sustainable lifestyle choices. The car share club is one of many alternative reflexive modes of consumption discernible in the ecovillage. There are, for example, egg clubs, bread clubs and a weekly farmers market. These are all primarily about enacting "sustainability" in the everyday, rather than signalling an anti-market discourse per se (cf. 
Bardhi and Eckhardt 2012). This community has therefore moved beyond problematizing sustainable challenges to creating infrastructures that support more sustainable practices. This community is capable of ingenuous self-appraisal, members are immersed in a reflexive culture, one which calls on then to consider the very discourses to which they subscribe.

\section{Fostering Critical Engagement}

Members are not just sustainable consumers, they are informed citizens capable of engaging with these discourses at a very high level, and of understanding the tensions and challenges which plague the green agenda. The final tactic which we explore involves critical engagement with prevailing discourses. For example, in the following passage Enda questions the current iteration of sustainability:

"Because when you talked about sustainability, I mean it looked, although it didn't really mean this, it looked like we were trying to sustain a system that probably was not working, that was unjust, that was only working for a very small percentage of the planet. And we were talking about sustainability, not that that's what we meant. We meant to try and reach a place where our systems could be sustained in the long term.... it's resilient communities that we're nurturing. It is still sustainable communities of course, but communities that can adapt and cope with the challenges that are facing us now." (Enda)

Enda expresses his concerns about how sustainability is framed, how it may be understood in other contexts. He emphasises the importance of language and of interpretation. His definition is succinct; sustainability is "a place where our systems could be sustained in the long term". Resilience, the ability to bounce back after a shock, is an important aide to sustainability (Barr and Devine-Wright 2012; Callaghan and Colton 2008). The community has taken on board the importance of resilience and reframed their objectives to reflect this new knowledge. 
Critical discursive engagement pervades within this community. Members complement on-going development in sustainability studies with reflection and re-articulation of meaning. In this case, members frame and then reframe what 'sustainability' means through regular public dialogue. Thomas describes an interaction about sustainable consumption which embodies this ethos:

"One of the people at the eco-village, who has sadly since left, but she and her husband, circulated around on our electronic discussion board about what is the most environmentally friendly furniture to buy, where would they buy environmentally friendly furniture. Various people came in with suggestions about which shops had forest stewardship certified timber and certified wood, this went backwards and forwards and then one person said 'buy antiques' and then another 'just second hand'. Whatever the environmental impact is it has already happened with that stuff anyway, so you're not adding to it and arguably if you save it, in the case of an antique it probably isn't going to go into a landfill but this suite probably would have. So I'm giving it an extra lease of life. You obviously don't keep it out of the landfill forever perhaps." (Thomas)

This passages reveals the reflexive nature of this community, where reflexivity is the constant examination and reformation of social practices in "light of incoming information about those very practices, thus constitutely altering their character" (Giddens 1990; p.38). Members have created forums which enable articulation and nurture the criticality required to untangle "sustainable consumption" from the neoliberal logic in which it often inscribed (Chatzidakis, Maclaran, and Bradshaw 2012). The concept of sustainability, an ambiguous term in itself (Barr and Devine-Wright 2012), is complicated here by the need to identify "the most" sustainable furniture. Discourses, such as this, are continuously reframed through dialogue and debate (Autio, Heiskanen, and Heinonen 2009). In this case, the reuse of the product (not just spatially but also temporally) becomes a salient theme in the discussions and 
is the determining factor in their final decision (that second hand furniture is the most sustainable). This process undoes the sustainable versus unsustainable dichotomy as members create a sliding scale of sustainable furniture consumption. The scale begins at the markets sustainable offerings and culminates in the eschewal of these offerings in favour of discarded furniture. For members of this community, upon reflection, saving an object from the landfill is ultimately the 'most sustainable' option. This challenges both the traditional linear nature of the circle of consumption (Hetherington 2004, p. 159) and the conventional understanding of sustainable products.

This kind of interaction is the norm in the everyday life of the ecovillage, in this way reflexivity around living sustainably is fostered. Members interrogate not just their consumption and lifestyle choices but the discursive rubrics which guide them. Practices which are underpinned by seemingly reified discourses are also interrogated and realigned. The community has developed a reflexive culture, it is a hugely important part of their life and shapes much of their communication:

"I mean we do put ourselves a lot under the microscope anyway and we do a lot of soul searching and naval gazing and all the rest of it with member's meetings and the rest of it, all of these issues [the sustainability of the community] are discussed, some would say ad nauseam but certainly discussed half to death anyway" (David)

David's description reveals the constancy and depth of reflexivity in this community. Reflexivity is the outcome of the tactic to foster critical engagement through interrogation, discussion and debate. Members make space for this kind of interaction in their daily lives, and welcome this reflexivity. Its effect in this context is that meaning is fluid, continuously framed and re-framed. Reflexivity is the defining feature of CJEV and is part of the social fabric of this community. It is sustained by the members' relationships with one another and by their commitment to the ongoing evolution of this sustainable community. 


\section{Discussion}

Organisations are socially constructed by way of conversations (Ford and Ford 1995), which both add to and draw on prevalent discursive practices (Brown and Coupland 2005). This research explored how the eco-discourse "sustainability" has been translated into a set of interrelated reflexive tactics in CJEV, an experimental space where people try to live sustainably. We investigated how the discourse is understood, enacted and embedded in the members' daily lives. Members have integrated a critical approach to consumption into their everyday. They habitually interrogate what "sustainability" actually means in terms of consumption. Such discussions are "storyworthy" (Johnstone 2008), because they are implicated in the emergence of a counter discourse to prevailing hedonistic consumption discourses (Autio, Heiskanen, and Heinonen 2009). As a result, they serve to continually frame and reframe what is understood to be "sustainable consumption". In this way, the members not only educate each other, but problematize the relationships between production, consumption and disposition in ways that contest the DSP (Kilbourne, McDonagh, and Prothero 1997).

Members of this ecovillage offer important experiential insights into the challenges and achievements of living in a sustainable community. Within mainstream society the institutional infrastructures tend to support unsustainable consumption (de Coverly et al 2008; Holt 2012; Scott, Martin, and Schouten 2014). In an explicit effort to counteract this, these infrastructures are confronted and, importantly, alternative infrastructures are put in place to encourage and support more sustainable practices. In the context of CJEV, choosing a site in an existent town and close to a railway station was an effort to minimise the need for private transport. However, for some members, the rural location necessitated access to a car. As a result, the community reflexively and collaboratively created a workable solution in the form of the car share club. This allowed members to engage with the sustainability demands 
of living in an ecovillage while simultaneously giving them access to market places and spaces outside its borders. Overall, then, the ecovillage is an experimental context in which reflexivity, in its various configurations, is cultivated.

Members do not simply accept conventional definitions of sustainability (which are largely static in mainstream society) nor the related rubrics. Here we see how certain practices considered "sustainable" outside the context of the ecovillage, are experienced as less definitive within its boundaries, and purchases made at one point in time according to accepted "sustainable criteria" are reimagined as these criteria are framed and reframed through critical engagement and reflexivity. Members take advantage of spaces shared with guests in an attempt to engender similar levels of engagement and reflexivity. They do this by encouraging guests to acknowledge that consumption does not exist in a vacuum. Rather, consumption is flanked by production and disposition (de Coverly et al., 2008), processes often masked by the DSP (Kilbourne, McDonagh and Prothero 1997). Thus, these tactics, communicative in nature, are intended to unveil and unsilence certain practices. In this way they encourage and engender reflexivity in the wider community. Once recontextualised and viewed as a much larger system of reflexive tactics the true depth and complexity of this community becomes apparent.

CJEV is a reflexive community evidenced by the degree of engagement and criticality that informs what they say and, more importantly, what they do, as they enact sustainability in the everyday. Reflexivity has allowed members to unveil routine behaviours and create alternative infrastructures that better support sustainability. Debate and discussion, then, are surprisingly effective tactics that encourage reflexivity, criticality and ultimately, change.

The social and spatio-temporal context of this ecovillage is important. This is a conglomerate of highly motivated individuals, most of whom take an active role in both setting the community's sustainable agenda and enacting it. Its physical location - within an 
existing village in rural Ireland brings specific challenges and opportunities which inform and dictate what is possible. Informed by new insights and new technologies, this is a very different ecological solution to those that characterised the early phase of ecovillage development. Thus, it can be best appreciated as a $21^{\text {st }}$ Century solution. But the temporal influence is more than simply this. Rather, the continual framing and reframing of meaning and everyday enactment

that what constituted "sustainable" at one point in time may be undone at yet another (Giddens and Pierson 1998). This vividly illustrates how consumption choices are situated within, and, are informed, by the socio-cultural and spatio-temporal contexts in which they find themselves (Dolan 2002; Chatzidakis, Maclaran and Bradshaw 2012).

\section{Conclusion}

This study enhances understanding of how the "sustainability" discourse is socially embedded and enacted in the everyday. CJEV positions itself as a pragmatic and reflexive sustainable community, an alternative to both radical ecological self-contained communes (Schehr 1997) and to conventional society (see Kilbourne, McDonagh, and Prothero 1997). The members have created a space where the DSP is critiqued and its deficiencies are addressed via the confrontation of routine behaviours, the creation of alternative infrastructures that facilitate more sustainable behaviours and through encouraging critical engagement and reflexivity. They avoid a head on confrontation with the DSP, by being open to and maintaining links with the locale and, to various extents, the market (physical and political). Such a position opens up scepticism of the role and value of the ecovillage by both radical activism and market perspectives (Prothero and Fitchett 2000). It is this compromised position however, that offers valuable insights into the sustainability debate. Importantly, we 
begin to truly appreciate how this reinforces how space and place are inextricably implicated in issues of ethics, ecology, and politics (Chatzidakis, Maclaran and Bradshaw 2012).

It is important to understand the contexts in which consumers make situated and complex decisions (Heath et al. 2014). The ecovillage brings tensions associated with sustainable living into focus, revealing the real conflicts and challenges of living sustainably in Western Capitalism. Importantly, these are closer to the challenges faced by mainstream consumers than would be the case with more radical sustainable communities (for example Ecovillage Ithaca). Consequently, policy makers wishing to promote sustainability agendas could look to communities such as CJEV in order to find other expressions of, and responses to, these important issues. For example, the problematisation of energy production is a common theme within the sustainability discourse (Kilbourne and Carlson 2008; Seyfang 2004). The tactics employed here to encourage reflexivity seem surprisingly effective. They could easily be adapted for other contexts. Care must be taken, however, to appreciate the particularities of each context, so that problematic practices are addressed with bespoke responses.

CJEV is ambitious in terms of its transformational aspirations and tenacious in its approach. We cannot yet determine if it will fulfil its ambitions, or whether, like many other social experiments, it will disintegrate or be absorbed by mainstream society. However, it is actively producing a reflexive space where alternative discourses can be explored, where infrastructures can be challenged, and where reflexive tactics can be implemented. By its own standards, measured against the most stringent environmental criteria, it has already achieved a great deal (for example: low carbon footprint, the evolution of the described systems and the creation of the CSA). Equally, however, by these very same standards, it still has some way to go (for example: onsite zero carbon energy production, a larger off-site CSA membership). 


\section{References}

Alvesson, Mats and Dan Karreman (2000), "Varieties of Discourse: On the Study of Organizations through Discourse Analysis," Human Relations, 53 (9), 1125-49.

Askegaard, Søren and Jeppe Tolle Linnet (2011), "Towards an epistemology of consumer culture theory: Phenomenology and the context of context," Marketing Theory, 11 (4), $381-404$.

Assadourian, Erik (2010), “Transforming Cultures: From Consumerism to Sustainability,” Journal of Macromarketing, 30 (2), 186-91.

Autio, Minna, Eva Heiskanen, and Visa Heinonen (2009), 'Narratives of ' green ' consumers - the antihero, the environmental hero and the anarchist," Journal of Consumer Behaviour, 53 (8), 40-53.

Bardhi, Fleura and Giana M. Eckhardt (2012), “Access-Based Consumption: The Case of Car Sharing," Journal of Consumer Research, 39 (4), 881-98.

Barr, Stewart and Patrick Devine-Wright (2012), "Resilient communities: sustainabilities in transition," Local Environment, 17 (5), 525-32.

Berger, Peter L. and Thomas Luckmann (1966), The Social Construction of Reality: A Treatise in the Sociology of Knowledge, London: Penguin Books Limited.

Blommaert, Jan (2005), Discourse: Key Topics in Sociolinguistics, New York: Cambridge University Press.

Borucke, Michael, Alessandro Galli, Katsunori Iha, Scott Mattoon, Juan Morales, Pati Poblete, and Mathis Wackernagal (2012), “The National Footprint Accounts , 2012 
edition," Global Footprint Network, Oakland, CA, USA.

Boström, Magnus, Andreas Føllesdal, Mikael Klintman, Mads P. Sørensen, and Michele Micheletti (2004), “Studying Political Consumerism," in Political Consumerism: Its motivations, power, and conditions in the Nordic countries and elsewhere, M. Boström, A. Føllesdal, M. Klintman, M. P. Sørensen, and M. Micheletti, eds., Oslo: Norden, 924.

Brown, Andrew D. and Christine Coupland (2005), "Sounds of silence:graduate trainees, hegemony and resistance.," Organization Studies, 26 (7), 1049-69.

Bryant, Raymond L. and Michael K. Goodman (2004), “Consuming Narratives: The Political consumption the ecology of 'alternative' consumption," Transactions of the Institute of British Geographers, 29 (3), 344-66.

Callaghan, Edith G. and John Colton (2008), "Building sustainable \& resilient communities: A balancing of community capital," Environment, Development and Sustainability, 10 (6), 931-42.

Chatzidakis, Andreas, Gretchen Larsen, and Simon Bishop (2014), "Farewell to Consumerism: Countervailing Logics of Growth in Consumption," Ephemera: Theory and Politics in Organization, 14 (4), 753-64.

_ of ethical and green consumption," Journal of Marketing Management, 28 (3-4), 494515.

Chitwere, Tendai (2010), "Equity in Sustainable Communities: Exploring Tools from Environmental Justice and Political Ecology,” Natural Resources Journal, 50, 315-39. Clarke, Nick (2008), “From ethical consumerism to political consumption'," Journal of Business Ethics, 2 (6), 1870-84.

Connolly, John and Andrea Prothero (2008), “Green Consumption: Life-politics, risk and 
contradictions," Journal of Consumer Culture, 8 (1), 117-45.

de Coverly, Edd, Pierre McDonagh, Lisa O’Malley, and Maurice Patterson (2008), “Hidden

Mountain: The Social Avoidance of Waste,” Journal of Macromarketing, 28 (3), 289303.

Craig-Lees, Margaret and Constance Hill (2002), "Understanding Voluntary Simplifiers," Psychology and Marketing, 19 (2), 187-210.

Cunningham, Paul (2014), "Exploring the efficacy of consensus-based decision-making," International Journal of Housing Markets and Analysis, 7 (2), 233-53.

Denzin, Norman K. (2003), “Performing [Auto] Ethnography Politically,” Review of Education, Pedagogy, and Cultural Studies, 25 (3), 257-78.

van Dijk, Teun A. (2006), “Ideology and discourse analysis,” Journal of Political Ideologies, $11(2), 115-40$.

Dolan, Paddy (2002), “The Sustainability of 'Sustainable Consumption,'” Journal of Macromarketing, 22 (2), 170-81.

Ergas, Christina (2010), “Organization \& Environment A Model of Sustainable Living : Collective Identity in an Urban Ecovillage,” Organization \& Environment, 23 (1), 32 54.

Ford, Jeffrey D. and Laurie W. Ford (1995), “The role of conversations in producing intentional change in organizations," Academy of Management. The Academy of Management Review.

Giddens, Anthony and Christopher Pierson (1998), Conversations with Anthony Giddens: Making Sense of Modernity, Stanford University Press.

Guillard, Valérie and Dominique Roux (2014), “Macromarketing Issues on the Sidewalk: How 'Gleaners' and 'Disposers' (Re)Create a Sustainable Economy.,' Journal of Macromarketing, 34 (3), 291-312. 
Halkier, Bente (2001), "Routinisation or Reflexivity? Consumers and Normative Claims for Environmental Consideration," in Ordinary Consumption (Studies in Consumption and Markets), J. Gronow and A. Warde, eds., London: Routledge, 272.

Harrison, Rob, Terry Newholm, and Deirdre Shaw (2005), "Introduction," in The Ethical Consumer, R. Harrison, T. Newholm, and D. Shaw, eds., London: Sage Publication Ltd., $1-8$.

Heath, Teresa, Lisa O’Malley, Matthew Heath, and Vicky Story (2014), “Caring and Conflicted: Mothers??? Ethical Judgments about Consumption,” Journal of Business Ethics, 1-14.

Hetherington, Kevin (2004), "Secondhandedness: consumption, disposal, and absent presence," Environment and Planning D: Society and Space, 22 (1), 157-73.

Hobson, Kersty (2002), “Competing Discourses of Sustainable Consumption : Does the ' Rationalisation of Lifestyles ' Make Sense ? Competing Discourses of Sustainable Consumption : Does the 'Rationalisation of Lifestyles ' Make Sense ?,” Envirnomental Politics, 11 (2), 95-120.

- (2003), “Thinking Habits into Action: the role of knowledge and process in questioning household consumption practices," Local Environment, 8 (1), 95-112.

Holt, Douglas B. (2012), “Constructing Sustainable Consumption: From Ethical Values to the Cultural Transformation of Unsustainable Markets," The ANNALS of the American Academy of Political and Social Science, 644 (1), 236-55.

Ilmonen, Kaj (2001), “Sociology; Consumption and Routine,” in Ordinary Consumption, J. Groncow and A. Warde, eds., New York: Routledge, 9-24.

Johnstone, Barbara (2008), Discourse Analysis, Singapore: Wiley-Blackwell.

Kilbourne, William E. (2010), "Facing the Challenge of Sustainability in a Changing World: An Introduction to the Special Issue," Journal of Macromarketing, 30 (2), 109-11. 
and Suzanne C. Beckmann (1998), "Review and Critical Assessment of Research on

Marketing and the Environment.," Journal of Marketing Management, 14 (6), 513-32. and L. Carlson (2008), “The Dominant Social Paradigm, Consumption, and

Environmental Attitudes: Can Macromarketing Education Help?,’ Journal of Macromarketing, 28, 106-21.

- Pierre McDonagh, and Andrea Prothero (1997), "Sustainable consumption and the quality of life: A macromarketing challenge to the dominant social paradigm," Journal of Macromarketing, 17 (1), 4-24.

Kirby, Andy (2003), "Redefining social and environmental relations at the ecovillage at Ithaca: A case study,” Journal of Environmental Psychology, 23 (3), 323-32.

Kirby, Peadar (2014), “Cloughjordan Ecovillage,” (accessed September 15, 2015), [available at http://www.peadarkirby.ie/index.php/ecovillage/cloughjordan-ecovillage].

Kornberger, M and Andrew D. Brown (2007), “Ethics' as a discursive resource for identity work," Human Relations, 60 (3), 497-518.

Kozinets, Robert V. (2002), “Can Consumers Escape the Market? Emancipatory Illuminations from Burning Man,” Journal of Consumer Research, 29 (1), 20-38.

Machin, David (2013), "What is multimodal critical discourse studies?," Critical Discourse Studies, 10 (4), 347-55.

McDonagh, Pierre and Andrea Prothero (2014a), "Sustainability marketing research: past, present and future," Journal of Marketing Management, 30 (11-12), 1186-1219.

— and (2014b), "Introduction to the Special Issue: Sustainability as Megatrend I," Journal of Macromarketing, 34 (May), 248-52.

Micheletti, Michele (2003), Political Virtue and Shopping, Basingstoke: Palgrave Macmillan. Mittelstaedt, John D., Clifford J. Shultz, William E. Kilbourne, and Mark Peterson (2014), “Sustainability as Megatrend: Two Schools of Macromarketing Thought," Journal of 
Macromarketing, 34 (February), 253-64.

Moisander, Johanna and Sinikka Pesonen (2002), "Narratives of sustainable ways of living: constructing the self and the other as a green consumer," Management Decision, 40 (4), $329-42$.

Moraes, Caroline, Isabelle Szmigin, and Marylyn Carrigan (2010), "Living production engaged alternatives: An Examination of new consumption communities," Consumption, Markets and Culture, 13 (3), 273-98.

O’Sullivan, Terry (2007), “Get MediaSmart®: A critical discourse analysis of controversy around advertising to children in the UK," Consumption Markets \& Culture, 10 (3), $293-314$.

Peattie, Ken (2010), “Green Consumption: Behavior and Norms," Annual Review of Environment and Resources, 35 (1), 195-228.

Pentina, Iryna and Clinton Amos (2011), “The Freegan phenomenon: anti-consumption or consumer resistance?," European Journal of Marketing, 45 (11/12), 1768-78.

Phillips, Nelson and Cynthia Hardy (2002), Discourse Analysis, London: Sage Publication Ltd.

Pickerill, Jenny (2015), "Cold Comfort? Reconceiving the Practices of Bathing in British Self-Build Eco-Homes," Annals of the Association of American Geographers, 105 (5), $1061-77$.

Portwood-Stacer, Laura (2012), “Anti-consumption as tactical resistance: Anarchists, subculture, and activist strategy," Journal of Consumer Culture, 12 (1), 87-105.

Prothero, Andrea and J. a. Fitchett (2000), “Greening Capitalism: Opportunities for a Green Commodity," Journal of Macromarketing, 20 (1), 46-55. and Pierre McDonagh (2015), "Introduction to the Special Issue: Sustainability as Megatrend II," Journal of Macromarketing, 35 (1), 7-10. 
Schaefer, Anja and Andrew Crane (2005), "Addressing sustainability and consumption," Journal of Macromarketing, 25 (1), 76-92.

Schehr, Robert (1997), Dynamic Utopia: Establishing Intentional Communities as a New Social Movement, Westport: Bergin \& Garvey.

Schor, Juliet B. (1998), The Overspent American: Why We Want What We Don't Need, London: Basic Books.

Scott, K., Diane M. Martin, and John W. Schouten (2014), "Marketing and the New Materialism," Journal of Macromarketing, 34 (April), 282-90.

Seyfang, Gill (2004), “Consuming Values and Contested Cultures: A Critical Analysis of the UK Strategy for Sustainable Consumption and Production," Review of Social Economy, $62(3), 323-38$.

_ (2006), "Ecological citizenship and sustainable consumption: Examining local organic food networks," Journal of Rural Studies, 22 (4), 383-95.

Sperling, Daniel and Deborah Gordon (2009), Two Billion Cars: Driving Toward Sustainability, Oxford: Oxford University Press.

The LivCom Awards (2014), "The International Awards for Liveable Communities," (accessed April 26, 2016), [available at http://www.livcomawards.com/2013awards/winners.htm].

The Village (2013), “Cloughjordan Ecovillage | Cloughjordan's Eco Neighbourhood Wins International Award in China," (accessed January 12, 2016), [available at http://www.thevillage.ie/cloughjordans-eco-neighbourhood-wins-international-award-inchina\%E2\%80\%A8\%E2\%80\%A8/].

(2016), “Cloughjordan Ecovillage | Our Project,” Our Project, (accessed February 4, 2016), [available at http://www.thevillage.ie/the-project/].

Vliet, Bas Van, Heather Chappells, and Elizabeth Shove (2005), Infrastructures of 
Consumption: Environmental Innovation in the Utility Industries, London: Earthscan.

i. In order to achieve this they have organised three primary activity groups (PAGs) including: the land use group, which attends to propagation, planting and land maintenance; the development group, which is responsible for construction management, development, site administration and sales; the Village Education and Research Group (VERT), which is in charge of educational and research aspects of the ecovillage and arranges all of the educational events, tours, visits and facilities (Kirby 2014). In addition to the PAGs there is an elected board of directors, they are responsible for the legal and financial oversight of the project and its corporate governance. 